\title{
Compositionally Screened Eutectic Catalytic Coatings on Halide Perovskite Photocathodes for Photoassisted Selective $\mathrm{CO}_{2}$ Reduction
}

Jie Chen, ${ }^{\dagger, \S, \ddagger \odot ~ J u n ~ Y i n, ~}{ }^{\dagger, \ddagger \odot ~ X i a o p e n g ~ Z h e n g, ~}{ }^{\dagger, \ddagger}$ Hassan Ait Ahsaine, ${ }^{\dagger, \S \odot}$ Yang Zhou, ${ }^{\dagger} \odot$ Chunwei Dong, Omar F. Mohammed, ${ }^{\dagger}$ Kazuhiro Takanabe, ${ }^{\dagger, \S}$ and Osman M. Bakr*, ${ }^{*}, \S$

${ }^{\dagger}$ Division of Physical Science and Engineering (PSE), and ${ }^{\S}$ KAUST Catalysis Center (KCC), King Abdullah University of Science and Technology (KAUST), Thuwal 23955-6900, Saudi Arabia

Supporting Information

ABSTRACT: Selective $\mathrm{CO}_{2}$ reduction via photoelectrocatalysis is a creative approach to alleviating the energy crisis and environmental deterioration as well as to producing value-added chemicals. A considerable challenge is the development of electrocatalysts and photoelectrocatalytic systems to selectively and efficiently produce a target product. Here, we report an efficient and selective photocathode for converting $\mathrm{CO}_{2}$ to $\mathrm{HCOOH}$ in aqueous solution. A rational compositional screening strategy was first applied to pinpoint $\mathrm{In}_{0.4} \mathrm{Bi}_{0.6}$ from ternary $\mathrm{In}-\mathrm{Bi}-\mathrm{Sn}$ alloys as the most $\mathrm{HCOOH}$-selective electrocatalyst composition among the electrocatalysts reported. A photocathode was then fabricated by coating the catalytic, protective, and conductive $\operatorname{In}_{0.4} \mathrm{Bi}_{0.6}$ alloy layer on a halide perovskite photovoltaic, effectively utilizing its low melting point eutectic molten state. The generated photovoltage assisted reduction of the overpotential by 680

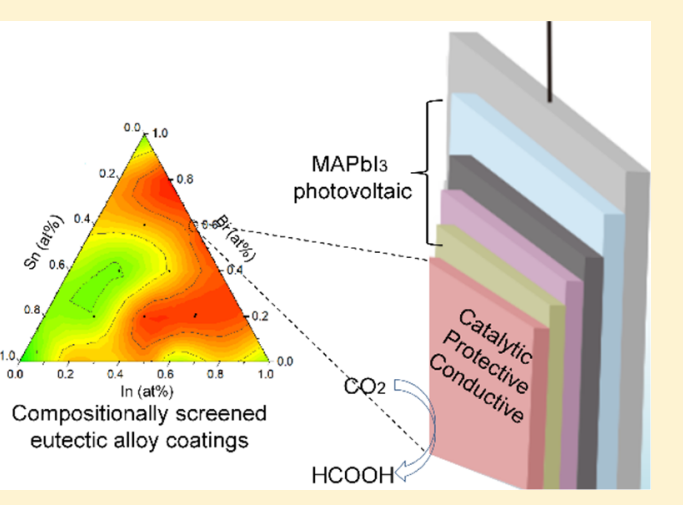
$\mathrm{mV}$ while producing a stable current for nearly exclusive $\mathrm{HCOOH}$ production under simulated AM 1.5G irradiation. This work provides a promising approach to achieving efficient and selective solar-fuel conversion.

$\mathrm{E}$ ver-increasing anthropogenic fossil fuel consumption and $\mathrm{CO}_{2}$ emission have caused a severe energy crisis and environmental deterioration. ${ }^{1}$ Selective $\mathrm{CO}_{2}$ reduction via photoelectrocatalysis is a creative approach to alleviating these issues as well as to producing value-added chemical fuels and feedstocks. ${ }^{2-9}$ Photoelectrocatalytic $\mathrm{CO}_{2}$ reduction directly converts $\mathrm{CO}_{2}$ to a variety of chemicals in integrated photoabsorber-electrocatalyst systems driven by solar and/or electrical energy. ${ }^{5,6}$ The products of $\mathrm{CO}_{2}$ reduction in aqueous media can be mixtures of formic acid $(\mathrm{HCOOH})$, carbon monoxide (CO), formaldehyde ( $\mathrm{HCHO})$, methane $\left(\mathrm{CH}_{4}\right)$, and $\mathrm{C}_{2}-\mathrm{C}_{3}$ hydrocarbons, largely depending on the electrocatalyst used. ${ }^{10-14}$ The subsequent separation of these products is generally energy- and time-consuming. ${ }^{15}$ Therefore, a considerable challenge in this field is to develop electrocatalysts and integrated photoelectrocatalytic systems to selectively and efficiently produce a singular or easily separable target product.

Among the possible products, formic acid is highly desirable because it can be used as a feedstock to synthesize various kinds of chemicals and as a hydrogen carrier for fuel cells. $^{10,12,14}$ In addition, formic acid is an economically viable chemical $^{10}$ that can be easily stored and transported. However, selective production of formic acid usually involves highly negative potentials for many reported electrocatalysts. ${ }^{16-21}$ Moreover, in terms of utilizing limitless solar energy to overcome the large energy barriers for $\mathrm{CO}_{2}$ reduction, highly active, selective, and stable photoelectrocatalytic $\mathrm{CO}_{2}-$ $\mathrm{HCOOH}$ systems are still lacking. ${ }^{6,22}$ Recent advances have demonstrated progress in the use of semiconductors (such as silicon, ${ }^{23} \mathrm{ZnTe}^{24}{ }^{24} \mathrm{InP},{ }^{25}$ and $\mathrm{Cu}_{2} \mathrm{ZnSnS}_{4}{ }^{26}$ ) integrated with electrocatalysts (such as $\mathrm{SnO}_{2}{ }^{23}$ polypyrrole, ${ }^{24}$ and ruthenium complexes ${ }^{25,26}$ ) for photoelectrocatalytic $\mathrm{CO}_{2}$ reduction to various products, including $\mathrm{HCOOH} .{ }^{22-30}$ However, there is still much room for improving the efficiency and, in particular, the selectivity.

Metal electrodes have been widely used for electrocatalytic $\mathrm{CO}_{2}$ reduction due to their robustness and superior catalytic activity. ${ }^{31,32}$ Metals such as $\mathrm{Pd}, \mathrm{Pb}, \mathrm{Co}, \mathrm{Hg}$, In, Bi, Cd, and $\mathrm{Sn}$ have been reported to favor formic acid production over other products. $^{31,32}$ Alloying of these metals has also been exploited to tune the selectivity and activity. For example, $\mathrm{CuSn},{ }^{14}$ $\mathrm{PdPt},{ }^{18} \mathrm{BiSn},{ }^{33} \mathrm{SnPb},{ }^{34}$ and $\mathrm{SnAg}^{35}$ alloys, among others, have

Received: April 8, 2019

Accepted: May 8, 2019

Published: May 8, 2019 

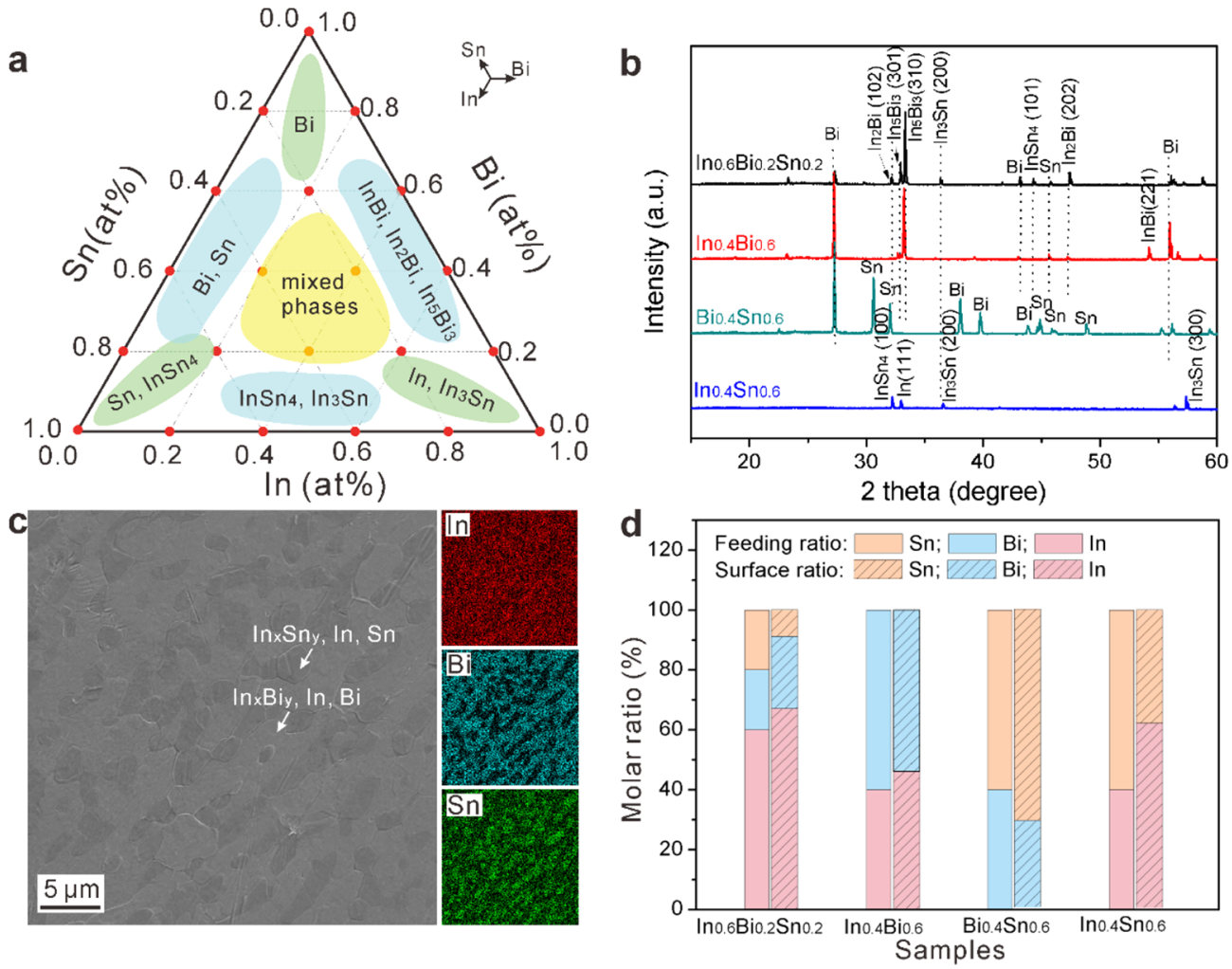

Figure 1. (a) Compositional diagram for the In-Bi-Sn alloys with the metal content varied in a $20 \%$ increment. The plausible crystal phases in each composition area are marked in the diagram. ${ }^{51}$ (b) Powder X-ray diffraction (XRD) patterns for the representative $\mathrm{In}_{0.4} \mathrm{Bi}_{0.6}$, $\mathrm{In}_{0.4} \mathrm{Sn}_{0.6}, \mathrm{Bi}_{0.4} \mathrm{Sn}_{0.6}$, and $\mathrm{In}_{0.6} \mathrm{Bi}_{0.2} \mathrm{Sn}_{0.2}$ samples. The characteristic peaks were identified according to the corresponding JCPDS cards (In: \#01-1042; Sn: \#02-0709; Bi: \#65-1215; InBi: \#32-0133; In ${ }_{2} B i$ : \#11-0566; $\operatorname{In}_{5} B_{3}$ : \#23-0850; ${ }^{52} \operatorname{In}_{3} \operatorname{Sn}_{2}$ \#07-0345; $\operatorname{InSn}_{4}$ : \#48-1547 ${ }^{50}$ ). (c) Scanning electron microscopy (SEM) and energy-dispersive X-ray (EDX) spectroscopic elemental mapping of $\operatorname{In}_{0.6} B_{0.2} S_{n_{0.2}}$ as an example. (d) Feed and surface molar ratios of the representative samples.

shown primarily formic acid formation at negative potentials. Moreover, researchers are increasingly finding the need to explore ternary alloy systems in order to achieve further advances in metal electrode efficiency and selectivity. ${ }^{36,37}$ For example, $\mathrm{He}$ et al. systematically screened $\mathrm{Cu}-\mathrm{Zn}-\mathrm{Sn}$ ternary alloys and found that $\mathrm{Cu}_{0.2} \mathrm{Zn}_{0.4} \mathrm{Sn}_{0.4}$ and $\mathrm{Cu}_{0.2} \mathrm{Sn}_{0.8}$ respectively convert $\mathrm{CO}_{2}$ to $\mathrm{CO}$ and $\mathrm{HCOOH}$ with high faradaic efficiency (FE) at low overpotentials that cannot be achieved by a single metal. ${ }^{37}$ Although the use of multiple component systems opens vast possibilities for enhancing $\mathrm{CO}_{2}$ reduction performance, the typical effort and chemical design involved in the systematic screening of such compositions create a prohibitive bottleneck against further exploitation.

Other than catalytic efficiency and selectivity, the materials compatibility and synergy considerations should also be taken into account when building a photoelectrocatalytic system. One particular concern is the photoabsorber in the system. Numerous semiconducting photoabsorbers are being used, such as InGaP/GaAs, ${ }^{38,39}$ silicon, ${ }^{40,41}$ and lead halide perovskites (LHPs). ${ }^{42-45}$ Among these materials, LHPs are highly promising and attractive due to their high absorption coefficient, large diffusion length, high charge mobility, and low-cost solution manufacturing of their devices. ${ }^{46-48}$ To date, the solar-to-electrical energy conversion efficiency of LHP photovoltaics rocketed to $24.2 \%$, ${ }^{49}$ while the solar-to-fuel conversion efficiency of the LHP-based photoelectrocatalytic cell has only reached $7.63 \%$ (denoted as ideal ratiometric power-saved efficiency) for water reduction hydrogen production, even loaded with noble metal $\mathrm{Pt}$ as the active site; $^{44}$ however, there is no report using LHP photocathodes for photoelectrocatalytic $\mathrm{CO}_{2}-\mathrm{HCOOH}$ conversion.

A critical issue facing LHPs is their vulnerability to air and moisture, which limits the long-term operation of LHP photoelectrocatalytic devices in aqueous solution. Moreover, LHPs are incompatible with high-temperature processing. Great efforts have been expended to making protective and conductive layers, such as Ti foil ${ }^{44}$ and Field's metal, ${ }^{42,45}$ on LHP photovoltaics. However, these layers were not catalytically active on their own, although in principle using a layer that is protective, conductive, and catalytically active could be beneficial for photoelectrocatalysis due to the facile charge transfer afforded by avoiding boundaries between the protective and catalytic layers.

Herein, we chose to explore $\mathrm{In}-\mathrm{Bi}-\mathrm{Sn}$ ternary alloys as potential protective and catalytic layers for photoelectrocatalytic systems, especially ones utilizing LHP photovoltaics. The reasons are as follows: (i) the low melting points of the $\mathrm{In}, \mathrm{Bi}$, and $\mathrm{Sn}$ metals (generally around $100{ }^{\circ} \mathrm{C}$ ) enable highthroughput compositional screening of the alloys by mechanical alloying methods; (ii) $\mathrm{MAPbI}_{3}$-based LHP photovoltaic materials and devices can stand up to $100{ }^{\circ} \mathrm{C}$; thus the low melting point at the eutectic molten state of the alloy facilitates a damage-free coating process on LHP devices; ${ }^{42}$ and (iii) In, $\mathrm{Bi}$, and $\mathrm{Sn}$ metals are $\mathrm{HCOOH}$-selective so that the alloys could probably provide highly selective electrocatalysts for exclusive $\mathrm{CO}_{2}-\mathrm{HCOOH}$ conversion.

As result of our judicious selection of the $\mathrm{In}-\mathrm{Bi}-\mathrm{Sn}$ ternary alloy system, we were able to systematical screen the ternary 

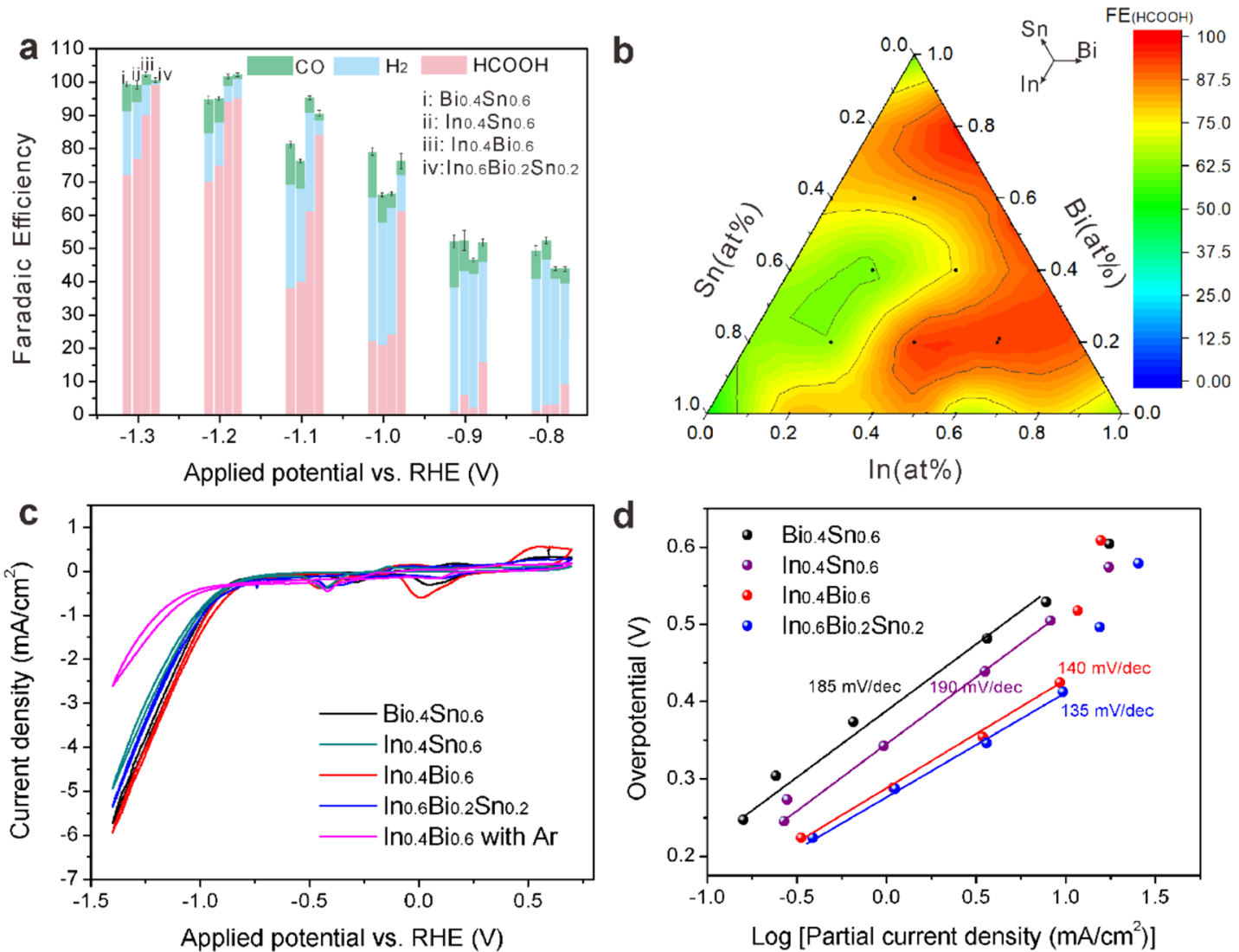

Figure 2. (a) FEs of $\mathrm{CO}, \mathrm{H}_{2}$, and $\mathrm{HCOOH}$ production for the representative $\operatorname{In}_{0.4} \mathrm{Bi}_{0.6}, \mathrm{In}_{0.4} \mathrm{Sn}_{0.6}, \mathrm{Bi}_{0.4} \mathrm{Sn}_{0.6}$, and $\mathrm{In}_{0.6} \mathrm{Bi}_{0.2} \mathrm{Sn}_{0.2}$ electrodes. (b) Ternary contour figure for $\mathrm{FE}_{\mathrm{HCOOH}}$ of the $\mathrm{In}-\mathrm{Bi}-\mathrm{Sn}$ alloy electrodes. The figure was drawn using the feed atomic ratio of the alloys. The black dots are the data points, and red zones indicate high $\mathrm{FE}_{\mathrm{HCOOH}}$ (c) Cyclic voltammograms (CVs) of the representative electrodes in 0.1 $\mathrm{M} \mathrm{KHCO}_{3}$ solution. The scan rate was $50 \mathrm{mV} / \mathrm{s}$. (d) Tafel plots for $\mathrm{HCOOH}$ production on the representative electrodes.

In-Bi-Sn alloys to obtain catalytic alloys that achieved the highest FE of nearly $100 \%$ for formic acid production. These champion compositions were then integrated as catalytic, protective, and conductive coatings onto $\mathrm{MAPbI}_{3}$-based photovoltaics in prototype photoelectrocatalytic devices for selective $\mathrm{CO}_{2}-\mathrm{HCOOH}$ conversion. We found that the In$\mathrm{Bi}-\mathrm{Sn}$ alloys possessing In- and Bi-rich surfaces showed the highest $\mathrm{FE}_{\mathrm{HCOOH}}$ in this material system. Our investigation shows that this exceptionally high figure of merit is due to the In, $\mathrm{Bi}$, and $\mathrm{In}_{5} \mathrm{Bi}_{3}$ phases having (i) low adsorption energies for $\mathrm{HCOO}^{*}$; (ii) large energy differences between the adsorption of the two $\mathrm{CO}_{2}$ reduction intermediates $\left(\mathrm{HCOO}^{*}\right.$ and $\mathrm{COOH}^{*}$ ); and (iii) large $\mathrm{H}^{*}$ adsorption energies. The perovskite photovoltaic provided a photovoltage as high as $680 \mathrm{mV}$ for the photoelectrocatalytic cell, which operated stably in aqueous solution and achieved a decent photoassisted electrolysis system efficiency of $7.2 \%$ for formic acid production at an applied potential of $-0.6 \mathrm{~V}$ vs reversible hydrogen electrode (RHE) under simulated AM 1.5G irradiation. This device represents an efficient photoelectrocatalytic cell exclusively for $\mathrm{CO}_{2}-\mathrm{HCOOH}$ conversion.

The In-Bi-Sn alloys were fabricated by mechanical alloying of $\mathrm{In}, \mathrm{Bi}$, and $\mathrm{Sn}$ metals protected in paraffin oil at $300{ }^{\circ} \mathrm{C}$. ${ }^{50}$ The alloys were then melted and pressed into thin-film electrodes, which were used for further characterizations and measurements. A series of $21 \mathrm{In}-\mathrm{Bi}-\mathrm{Sn}$ alloy electrodes was prepared with the relative $\mathrm{In}, \mathrm{Bi}$, and $\mathrm{Sn}$ molar ratios varied in a $20 \%$ increment (Figure 1a). The experimental details are described in the Supporting Information and illustrated in Figure S1.

The alloying of the films was confirmed by XRD patterns and SEM images (Figure $1 \mathrm{~b}, \mathrm{c}$ ). $\mathrm{In}_{0.4} \mathrm{Bi}_{0.6}, \mathrm{In}_{0.4} \mathrm{Sn}_{0.6}, \mathrm{Bi}_{0.4} \mathrm{Sn}_{0.6}$, and $\mathrm{In}_{0.6} \mathrm{Bi}_{0.2} \mathrm{Sn}_{0.2}$ were selected as representative samples for $\mathrm{XRD}$ comparison, as shown in Figure $1 \mathrm{~b}$, because they have moderate compositions and thus include the different alloy phases marked in Figure 1a. It can be observed that indium alloyed with bismuth and tin, forming $\operatorname{InBi}, \operatorname{In}_{2} \mathrm{Bi}$, and $\operatorname{In}_{5} \mathrm{Bi}_{3}$ phases and $\mathrm{InSn}_{4}$, and $\mathrm{In}_{3} \mathrm{Sn}$ phases, respectively. In contrast, bismuth and tin did not form alloyed phases; therefore, Bi and $\mathrm{Sn}$ were observed in the $\mathrm{Bi}-\mathrm{Sn}$ alloys. XRD patterns for the alloys of all compositions were also obtained, as shown in Figure S2. The alloys containing the same elements showed the same crystal phases as did the representative samples, while the intensities of the characteristic peaks for the dominant phases varied with the molar ratio.

We further took $\operatorname{In}_{0.6} \mathrm{Bi}_{0.2} \mathrm{Sn}_{0.2}$ ternary alloy as an example to investigate the surface microstructure as $\mathrm{In}_{0.6} \mathrm{Bi}_{0.2} \mathrm{Sn}_{0.2}$ consists of all of the phases and could thus have representative surface features. As shown in Figure 1c, the alloys possess an islandlike surface microstructure, and the islands show a sharp grayscale contrast relative to the other areas, implying that different elements are enriched in different areas on the surface. The EDX mapping shows that indium covers the entire surface, while bismuth and tin are distributed in different island-like areas, which is consistent with the XRD results indicating that indium alloys with bismuth and tin, whereas bismuth and tin do not alloy. Moreover, according to the quantitative elemental 


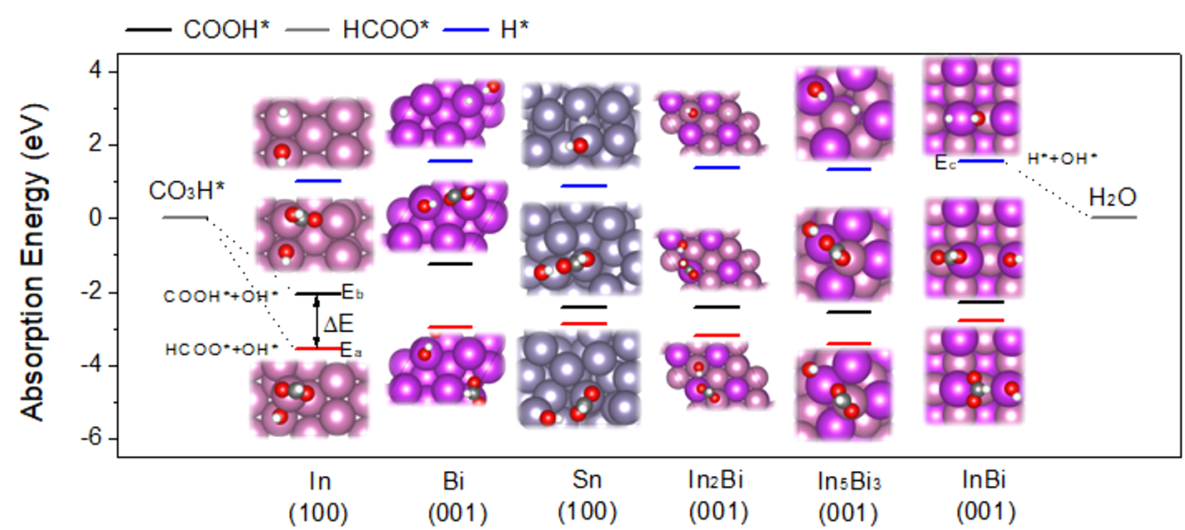

Figure 3. Calculated adsorption energy profiles of the intermediates of $\mathrm{CO}_{2}$ reduction for forming $\mathrm{CO}$ and $\mathrm{HCOOH}$ and $\mathrm{H}_{2} \mathrm{O}$ reduction for forming $\mathrm{H}_{2}$ on $\operatorname{In}(100), \operatorname{Bi}(001), \operatorname{Sn}(100), \operatorname{In}_{2} \mathrm{Bi}(001), \operatorname{In}_{5} \mathrm{Bi}_{3}(001)$, and $\operatorname{InBi}(001)$ surfaces. The energies of the $\mathrm{CO}_{2}$ reduction intermediates are relative to the energy of $\mathrm{CO}_{3} \mathrm{H}^{*}$, and the energies for the $\mathrm{H}_{2} \mathrm{O}$ reduction intermediates are relative to the energy of the $\mathrm{H}_{2} \mathrm{O}$ molecules adsorbed on the alloy surfaces.

analysis performed via EDX over a $40 \mu \mathrm{m} \times 40 \mu \mathrm{m}$ area (Figure 1d; all of the ratios are summarized in Table S1), the surface atomic ratios of the alloys are slightly different from the feed atomic ratios with the metals with a low melting point (In $<\mathrm{Sn}<\mathrm{Bi}$ ) tending to enrich on the surface. This phenomenon could be attributed, on the one hand, to alloy phase segregation $^{53,54}$ and, on the other hand, as the fabrication of the thin-film samples by a melting-pressing-cooling process, such that the metal with the lowest melting point enriched on the surface as it cooled after the other metals.

The performances of the alloy electrodes for $\mathrm{CO}_{2}$ electroreduction were evaluated by measuring the FEs and partial current densities in $0.1 \mathrm{M} \mathrm{KHCO}_{3}$ aqueous solution in a threeelectrode cell with continuous $\mathrm{CO}_{2}$ purge (experimental details are described in the Supporting Information). The $\mathrm{CO}_{2}$ reduction products from the representative $\mathrm{In}_{0.6} \mathrm{Bi}_{0.2} \mathrm{Sn}_{0.2}$, $\mathrm{In}_{0.4} \mathrm{Bi}_{0.6}, \mathrm{In}_{0.4} \mathrm{Sn}_{0.6}$, and $\mathrm{Bi}_{0.4} \mathrm{Sn}_{0.6}$ electrodes were $\mathrm{HCOOH}$ and $\mathrm{H}_{2}$ with a trace amount of $\mathrm{CO}$ at applied potentials of -0.8 to $-1.3 \mathrm{~V}$ vs RHE, as shown in Figure $2 \mathrm{a}$. The $\mathrm{FE}_{\mathrm{HCOOH}}$ of the alloys increased as the potentials became more negative, indicating that the alloys were still formic acid-selective catalysts, similarly to the individual $\mathrm{In}, \mathrm{Bi}$, and $\mathrm{Sn}$ metals. ${ }^{55}$ The $\mathrm{FE}_{\mathrm{HCOOH}}$ reached a plateau at -1.2 to $-1.3 \mathrm{~V}$ vs RHE for all of the samples, with the $\operatorname{In}_{0.6} \mathrm{Bi}_{0.2} \mathrm{Sn}_{0.2}$ and $\operatorname{In}_{0.4} \mathrm{Bi}_{0.6}$ alloys achieving the highest $\mathrm{FE}_{\mathrm{HCOOH}}$ values of $95-98 \%$ at -1.2 to $-1.3 \mathrm{~V}$ vs RHE. These samples stand out as highly selective electrocatalysts for formic acid production among previously reported ones (Table S2).

To screen the ternary alloys for formic acid production, the $\mathrm{FE}_{\mathrm{HCOOH}}$ at $-1.2 \mathrm{~V}$ vs $\mathrm{RHE}$ was taken as the principal criterion, and the data points for all of the alloy electrodes were visualized as a ternary contour figure (Figure $2 \mathrm{~b}$; see Table S1 for all the data points). The figure clearly shows that $\mathrm{FE}_{\mathrm{HCOOH}}$ is closely associated with the metal molar ratios. The alloys containing $\mathrm{In}-\mathrm{Bi}$ are generally more favorable for formic acid production than the other combinations. In particular, $\operatorname{In}_{0.4} \mathrm{Bi}_{0.6}$ and $\mathrm{In}_{0.6} \mathrm{Bi}_{0.2} \mathrm{Sn}_{0.2}$ are among the best, as indicated by the red zone of the contour figure, where high $\mathrm{FE}_{\mathrm{HCOOH}}$ values exceeding $95 \%$ at $-1.2 \mathrm{~V}$ vs RHE were achieved. Note that the overall FEs were less than $100 \%$ at less negative potentials ( -1.0 to $-0.8 \mathrm{~V}$ vs RHE), possibly due to the undesired metal redox reactions. ${ }^{56} \mathrm{We}$ further determined the onset potential of all of the metallic electrodes by taking the potentials enabling partial current density of $0.5 \mathrm{~mA} / \mathrm{cm}^{2}$ for $\mathrm{HCOOH}$ production as the criterion (Table S1). It can be seen that the onset potentials of all of the samples are very close at around $-0.9 \mathrm{~V}$ vs RHE, and several alloys $\left(\operatorname{In}_{0.2} \mathrm{Bi}_{0.8}, \mathrm{In}_{0.4} \mathrm{Bi}_{0.6}\right.$, and $\left.\mathrm{In}_{0.6} \mathrm{Bi}_{0.2} \mathrm{Sn}_{0.2}\right)$ exhibit onset potentials that are slightly more positive than $-0.9 \mathrm{~V}$ vs RHE.

The overall current densities of the representative samples are shown in Figure 2c with all of the data curves shown in Figure S3 and contour figures visualized in Figure S4. The figures show that the overall current densities of the alloys were similar, while the In-Bi alloys generally achieved current densities higher than those of the other alloys. Moreover, the In- and Bi-containing alloys showed higher partial current densities for formic acid than the other alloys (contour Figure $\mathrm{S} 4 \mathrm{~b}$ ), further indicating that the In- and Bi-containing alloys are favorable for formic acid formation. Moreover, although the resistivities of $\mathrm{In}_{0.4} \mathrm{Sn}_{0.6}$ and $\mathrm{Bi}_{0.4} \mathrm{Sn}_{0.6}$ are slightly smaller than those of $\operatorname{In}_{0.4} \mathrm{Bi}_{0.6}$ and $\mathrm{In}_{0.6} \mathrm{Bi}_{0.2} \mathrm{Sn}_{0.2}$ (see the Supporting Information for the measurement details), the small difference in resistance in the metallic electrode did not lead to appreciable difference in $\mathrm{CO}_{2}$ reduction performance. This indicates that the resistivity at the metal/electrolyte interface, instead of the resistivity in the metallic electrode, is the main factor effecting the $\mathrm{CO}_{2}$ reduction performance.

Detailed kinetics studies of the representative $\operatorname{In}_{0.6} \mathrm{Bi}_{0.2} \mathrm{Sn}_{0.2}$, $\mathrm{In}_{0.4} \mathrm{Bi}_{0.6}, \quad \mathrm{In}_{0.4} \mathrm{Sn}_{0.6}$, and $\mathrm{Bi}_{0.4} \mathrm{Sn}_{0.6}$ alloy electrodes were performed by electrochemical impedance spectroscopy (EIS, Figure S5) and Tafel plots (Figure 2d). The EIS results show that the $\operatorname{In}_{0.4} \mathrm{Bi}_{0.6}$ electrode presented a semicircle with a small radius, suggesting a lower electron transfer resistance than the other samples. Together with the measurements of the resistivity of the metallic electrode, this result implies better conductivity (especially at the metal/electrolyte interface) and separation efficiency of the charge carriers, which promotes the $\mathrm{CO}_{2}$ reduction process on $\mathrm{In}_{0.4} \mathrm{Bi}_{0.6}$. The representative electrodes yielded slopes of $135-190 \mathrm{mV} / \mathrm{dec}$ for formic acid production, as shown in the Tafel plots, which suggest that the rate-determining step of $\mathrm{CO}_{2}$ electroreduction on the $\mathrm{In}-\mathrm{Bi}-\mathrm{Sn}$ alloy electrodes is the first electron transfer for the formation of $\mathrm{CO}_{2}{ }^{\bullet-57-59}$ This transfer is accepted as the initial step of $\mathrm{CO}_{2}$ reduction on most metallic electrodes. ${ }^{58,59}$ Note that there is a deviation from linear correlation (especially for the $\mathrm{In}_{0.4} \mathrm{Bi}_{0.6}$ and $\mathrm{In}_{0.6} \mathrm{Bi}_{0.2} \mathrm{Sn}_{0.2}$ samples) in the Tafel plot at high overpotentials, which is commonly known to be due to mass transport limitation. Among the samples, the 

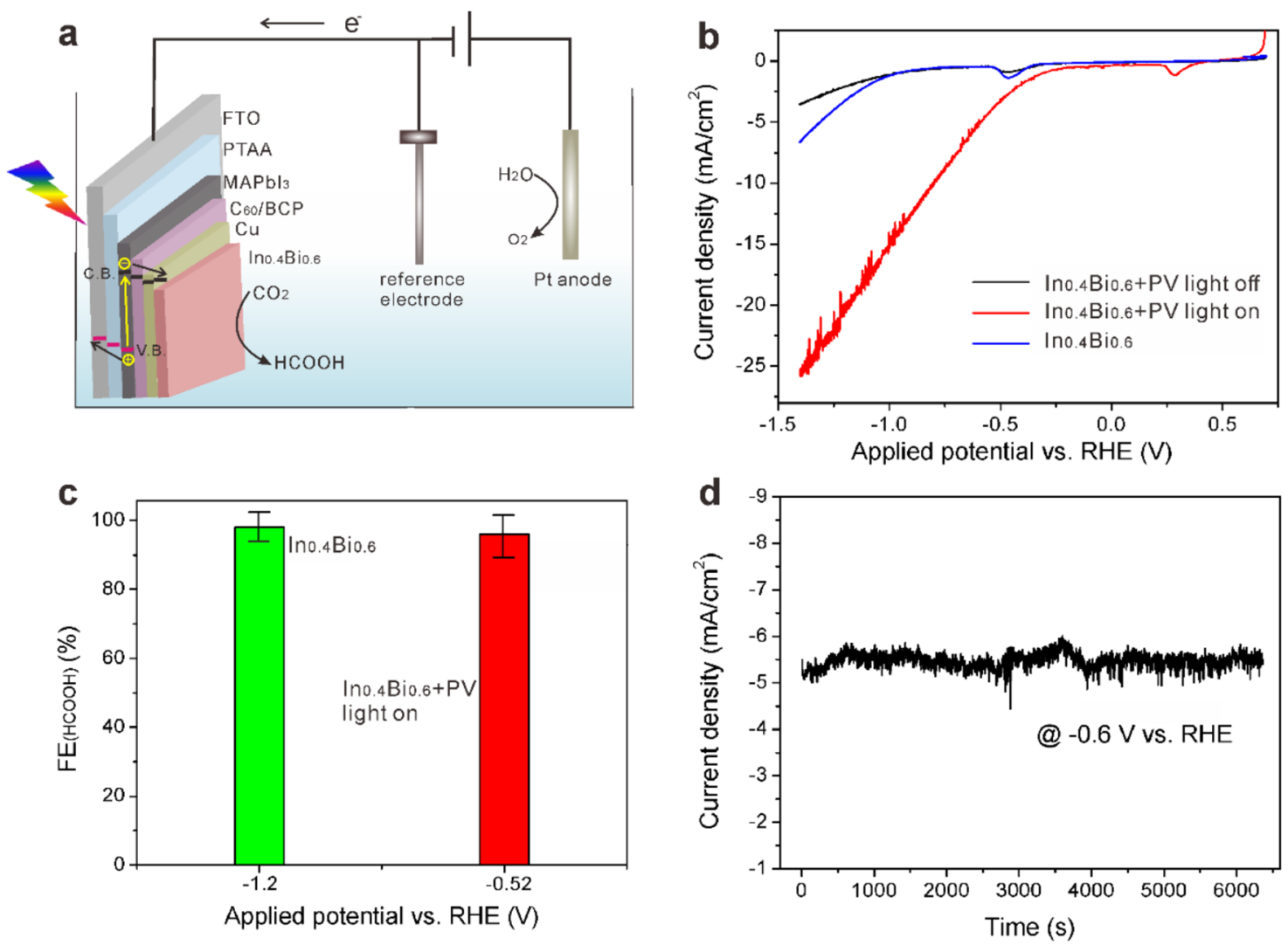

Figure 4. (a) Schematic illustration of the photoelectrocatalytic test of the $\operatorname{In}_{0.4} \mathrm{Bi}_{0.6}$-coated perovskite photocathode using a standard threeelectrode system. The photocathode is illuminated from the FTO side. The relative energy levels are illustrated to indicate the direction of electron/hole flow in the device. (b) Current density vs potential behavior for the electrodes in $\mathrm{CO}_{2}$-saturated $0.1 \mathrm{M} \mathrm{KHCO}_{3}$ with or without simulated AM 1.5G irradiation. (c) Comparison of $\mathrm{FE}_{\mathrm{HCOон}}$ values obtained using the $\mathrm{In}_{0.4} \mathrm{Bi}_{0.6}$ electrode and $\mathrm{In}_{0.4} \mathrm{Bi}_{0.6} /$ perovskite photocathode. (d) Stability test of the $\mathrm{In}_{0.4} \mathrm{Bi}_{0.6} /$ perovskite photocathode under $\mathrm{AM} \mathrm{1.5G}$ irradiation at $-0.6 \mathrm{~V}$ vs RHE.

$\mathrm{In}_{0.6} \mathrm{Bi}_{0.2} \mathrm{Sn}_{0.2}$ and $\mathrm{In}_{0.4} \mathrm{Bi}_{0.6}$ electrodes exhibited lower Tafel slopes than the others, indicating that these samples exhibit faster reaction kinetics for the $\mathrm{CO}_{2}$ reduction than the other alloys.

We further attempted to understand the selectivity of the $\mathrm{In}-\mathrm{Bi}-\mathrm{Sn}$ alloys by calculating and comparing the adsorption energies of the $\mathrm{CO}_{2}$ reduction and $\mathrm{H}_{2} \mathrm{O}$ reduction intermediates on the alloy surfaces. For $\mathrm{CO}_{2}$ reduction, the two intermediates of $\mathrm{COOH}^{*}$ and $\mathrm{HCOO}^{*}$ were considered for the computational analysis of $\mathrm{CO}$ and $\mathrm{HCOO}^{-}$production, the energy levels of which were compared relative to adsorbed bicarbonate $\left(\mathrm{CO}_{3} \mathrm{H}^{*}\right)$ species. ${ }^{33}$ On the contrary, for $\mathrm{H}_{2}$ evolution, $\mathrm{H}^{*}$ energy levels were calculated relative to adsorbed $\mathrm{H}_{2} \mathrm{O}$ on the alloy surfaces.

The corresponding energy profiles are depicted in Figure 3. On the In, Bi, and In-Bi alloy surfaces, the adsorption energies of HCOO* $\left(E_{\mathrm{a}}\right)$ and the energy differences $(\Delta E)$ between the adsorption of the two intermediates $\left(\mathrm{HCOO}^{*}\right.$ and $\mathrm{COOH}^{*}$ ) are respectively more negative and larger than those on the $\mathrm{Sn}$ surface. The more negative $E_{\mathrm{a}}$ and larger $\Delta E$ values indicate that the In- and Bi-containing alloys are more favorable for $\mathrm{HCOOH}$ production instead of $\mathrm{CO}$ production than the Sncontaining alloys for $\mathrm{CO}_{2}$ reduction reactions. However, for $\mathrm{H}^{*}$ formation, the $\mathrm{Sn}$ surface shows a smaller adsorption energy $\left(E_{c}\right)$ than the other alloy surfaces, which suggests that the Sn-containing alloys could be more favorable for $\mathrm{H}_{2}$ production than the In- and Bi-containing alloys.
The In-Bi alloys ( $\left.\operatorname{InBi}, \operatorname{In}_{5} \mathrm{Bi}_{3}, \mathrm{In}_{2} \mathrm{Bi}\right)$ showed almost equally large $\mathrm{H}^{*}$ adsorption energies, making them unfavorable for $\mathrm{H}_{2} \mathrm{O}$ reduction. In contrast, for $\mathrm{CO}_{2}$ reduction, $\mathrm{In}_{5} \mathrm{Bi}_{3}$ showed more negative $E_{\mathrm{a}}$ and larger $\Delta E$ values than the other alloy phases; thus, $\mathrm{In}_{5} \mathrm{Bi}_{3}$ could be the most $\mathrm{HCOOH}$-selective alloy phase. This finding partially corroborates the experimental results indicating that the $\mathrm{In}_{0.4} \mathrm{Bi}_{0.6}$ and $\mathrm{In}_{0.6} \mathrm{Bi}_{0.2} \mathrm{Sn}_{0.2}$ alloys containing largely dominant $\mathrm{In}_{5} \mathrm{Bi}_{3}$ phases (XRD patterns in Figure 1b) achieved higher $\mathrm{HCOOH}$ selectivity. Here we should note that some ternary Sn-containing alloys (for example, $\mathrm{In}_{0.6} \mathrm{Bi}_{0.2} \mathrm{Sn}_{0.2}$ ) did stand out from others (in terms of selectivity and efficiency), despite containing a small amount of $\mathrm{Sn}$. This behavior is very likely due to the $\mathrm{In}, \mathrm{Bi}$, and $\mathrm{In}_{5} \mathrm{Bi}_{3}$ phases present, even in those $\mathrm{Sn}$-containing compositions, that dominate the material's $\mathrm{CO}_{2}$ to $\mathrm{HCOOH}$ conversion activity.

Thus, the alloys containing $\mathrm{In}, \mathrm{Bi}$, and $\mathrm{In}_{5} \mathrm{Bi}_{3}$ could be the optimal catalytic alloys for selective $\mathrm{HCOOH}$ production. We further fabricated a catalytic alloy-coated halide perovskite photocathode by selecting $\operatorname{In}_{0.4} \mathrm{Bi}_{0.6}$ as the catalytic coating layer and a $\mathrm{MAPbI}_{3}$-based halide perovskite photovoltaic with a high power conversion efficiency of $18.7 \%$ (Figure S6). $\mathrm{MAPbI}_{3}$ has a small band gap of $1.5 \mathrm{eV}$ and, therefore, absorbs a wide spectrum of light (Figure S7). The low melting point of $\mathrm{In}_{0.4} \mathrm{Bi}_{0.6}$ near the eutectic state of $\mathrm{In}-\mathrm{Bi}$ alloys facilitates the coating process at temperatures below $100{ }^{\circ} \mathrm{C}$. The thickness of the $\operatorname{In}_{0.4} \mathrm{Bi}_{0.6}$ layer in the photocathode is $200 \mu \mathrm{m}$. The structure of the photocathode is shown in Figure 4a, and the fabrication process is described in detail in the Supporting 
Information. The approximate energy levels of the layers in the photoelectrode are shown in Figure S8. Driven by the energylevel difference, the photoexcited charge carriers from the $\mathrm{MAPbI}_{3}$ will be separated by the charge-selective contacts: the hole transport layer (PTAA) and the electron transport layer (C60/BCP). Subsequently, the electrons will flow to the $\mathrm{In}_{0.4} \mathrm{Bi}_{0.6}$ coating layer to participate in the $\mathrm{CO}_{2}$ reduction reactions. Notably, the current density of the $\operatorname{In}_{0.4} \mathrm{Bi}_{0.6} /$ perovskite photocathode under illumination was greatly enhanced relative to that of the metal electrodes alone (Figure $4 \mathrm{~b}$ ), indicating an effective photoassisted electrocatalytic $\mathrm{CO}_{2}$ reduction process. The $\mathrm{In}_{0.4} \mathrm{Bi}_{0.6} /$ perovskite photocathode showed negligible current density in the dark, confirming that the enhanced current density originates from the photoassisted $\mathrm{CO}_{2}$ reduction instead of the electrochemical degradation of $\mathrm{MAPbI}_{3}{ }^{43}$

We propose that the present photoelectrochemical (PEC) system could be more compact and tunable than the photovoltaic + electrocatalytic $(\mathrm{PV}+\mathrm{EC})$ system for $\mathrm{CO}_{2}$ reduction. The reasons are that (i) $2.23 \mathrm{~V}$ will be needed to drive the $\mathrm{CO}_{2}$ reduction when $\mathrm{Pt}$ is used as the anode and an $\mathrm{In}_{0.4} \mathrm{Bi}_{0.6}$ electrode is used as the cathode, which will require three halide perovskite PV cells as one cell provides at most $1.06 \mathrm{~V}$, while the PEC system provides a compact and simpler structure by using only one cell with the additional voltage provided by the external circuit; (ii) $\mathrm{CO}_{2}$ reduction gives a specific product (or mixtures) at a specific potential that can be easily achieved in the PEC system by controlling the external circuit while the PV cells (or tandem PV cells) have to be carefully designed to provide a certain photovoltage to drive the $\mathrm{CO}_{2}$ reduction efficiently for a specific product.

With the $\operatorname{In}_{0.4} \mathrm{Bi}_{0.6} /$ halide perovskite photocathode, nearly $100 \% \mathrm{FE}$ for formic acid production could be achieved at a low applied potential of $-0.52 \mathrm{~V}$ vs RHE under AM $1.5 \mathrm{G}$ irradiation, representing a $680 \mathrm{mV}$ positive shift relative to the potential observed for the $\operatorname{In}_{0.4} \mathrm{Bi}_{0.6}$ electrode (Figure $4 \mathrm{c}$ ). We also calculated the onset potential shift of the $\mathrm{MAPbI}_{3} \mathrm{PV} / \mathrm{In}-$ $\mathrm{Bi}$ photoelectrode relative to the metallic $\mathrm{In}_{0.4} \mathrm{Bi}_{0.6}$ electrode. The onset potential was around $-0.83 \mathrm{~V}$ vs RHE for the metallic $\operatorname{In}_{0.4} \mathrm{Bi}_{0.6}$ electrode (Table S1) when taking the potential enabling a partial current density of $0.5 \mathrm{~mA} / \mathrm{cm}^{2}$ for $\mathrm{HCOOH}$ production as the criterion. After integration with the $\mathrm{MAPbI}_{3} \mathrm{PV}$, which provides a $680 \mathrm{mV}$ photovoltage, the onset potential of the $\mathrm{MAPbI}_{3} \mathrm{PV} / \mathrm{In}-\mathrm{Bi}$ photoelectrode shifted to $-0.15 \mathrm{~V}$ vs RHE. We further calculated the photoassisted electrocatalysis efficiency $\left(\eta_{\mathrm{PAE}}\right)^{23,60}$ to estimate the overall efficiency of the $\operatorname{In}_{0.4} \mathrm{Bi}_{0.6} /$ perovskite photocathode for selective $\mathrm{CO}_{2}$ reduction to $\mathrm{HCOOH}$, with the calculation details shown in the Supporting Information. Specifically, we used the current density $\left(5.5 \mathrm{~mA} / \mathrm{cm}^{2}\right)$ at an applied potential of $-0.6 \mathrm{~V}$ vs RHE to calculate the $\eta_{\mathrm{PAE}}$ because at $-0.6 \mathrm{~V}$ the system stably produced formic acid at nearly $100 \% \mathrm{FE}$ for at least $1.5 \mathrm{~h}$ (Figure $4 \mathrm{~d}$ ). A $\eta_{\mathrm{PAE}}$ of $7.2 \%$ was determined using our system for exclusive formic acid production. This photoelectrocatalytic cell is a highly selective system for converting $\mathrm{CO}_{2}$ to $\mathrm{HCOOH}$ with decent efficiency compared with the values reported in previous studies (Table S3). The efficiency of the system could be further enhanced by means of nanostructuralization of the $\mathrm{In}-\mathrm{Bi}$ catalytic layer to enable high current density and usage of an anode with a relatively low overpotential for water oxidation.

In summary, our selection of a low-melting point ternary $\mathrm{In}-\mathrm{Bi}-\mathrm{Sn}$ alloy system enabled a rational compositional screening strategy for identifying the most selective composition for electrochemical $\mathrm{CO}_{2}$-to-HCOOH conversion. $\operatorname{In}_{0.4} \mathrm{Bi}_{0.6}$ and $\mathrm{In}_{0.6} \mathrm{Bi}_{0.2} \mathrm{Sn}_{0.2}$, alloys containing dominant $\mathrm{In}_{5} \mathrm{Bi}_{3}$ phases were observed to be particularly $\mathrm{HCOOH}$-selective electrocatalysts, possibly because the $\mathrm{HCOO}^{*}$ intermediate is better stabilized on the $\operatorname{In}_{5} \mathrm{Bi}_{3}$ surfaces than on other alloy surfaces. By a simple low-temperature coating process, we fabricated a catalytic and protective $\operatorname{In}_{0.4} \mathrm{Bi}_{0.6}$ alloy coating on the LHP photovoltaic devices. The photoelectrocatalytic system operated stably in aqueous solution and achieved a photoassisted electrolysis system efficiency of $7.2 \%$ for highly selective formic acid production at an applied potential of $-0.6 \mathrm{~V}$ vs RHE under simulated AM 1.5G irradiation. Our ternary compositional screening strategy, together with the demonstration of a highly efficient and selective photoelectrocatalytic cell, provides a promising design methodology to achieve highly efficient and selective solar-fuel conversion.

\section{ASSOCIATED CONTENT}

\section{Supporting Information}

The Supporting Information is available free of charge on the ACS Publications website at DOI: 10.1021/acsenergylett.9b00751.

Experimental methods, additional XRD patterns, CV and EIS curves, contour figures for the current density, $J-V$ curves for the perovskite photovoltaic, as well as the quantitative performance comparison of the electrocatalysts (PDF)

\section{AUTHOR INFORMATION}

\section{Corresponding Author}

*E-mail: osman.bakr@kaust.edu.sa.

ORCID

Jie Chen: 0000-0002-2007-0896

Jun Yin: 0000-0002-1749-1120

Hassan Ait Ahsaine: 0000-0002-8423-9689

Yang Zhou: 0000-0003-4477-6532

Omar F. Mohammed: 0000-0001-8500-1130

Osman M. Bakr: 0000-0002-3428-1002

\section{Author Contributions}

${ }^{\ddagger}$ J.C., J.Y., and X.Z. contributed equally. J.C. and O.M.B. conceived the idea and designed the experiments. J.C. fabricated the photocathodes, performed all of the measurements, and wrote the paper. J.Y. performed the DFT calculations. X.Z. fabricated the perovskite photovoltaic. H.A.A. helped measure electrochemical performance. K.T. and O. F. M. assisted in revising the paper. All authors reviewed the paper.

\section{Notes}

The authors declare no competing financial interest.

\section{ACKNOWLEDGMENTS}

This work was supported by King Abdullah University of Science and Technology (KAUST).

\section{REFERENCES}

(1) McCollum, D. L.; Jewell, J.; Krey, V.; Bazilian, M.; Fay, M.; Riahi, K. Quantifying Uncertainties Influencing the Long-Term Impacts of Oil Prices on Energy Markets and Carbon Emissions. Nat. Energy 2016, 1, 16077. 
(2) Qiao, J.; Liu, Y.; Hong, F.; Zhang, J. A Review of Catalysts for the Electroreduction of Carbon Dioxide to Produce Low-Carbon Fuels. Chem. Soc. Rev. 2014, 43 (2), 631-675.

(3) Sato, S.; Arai, T.; Morikawa, T.; Uemura, K.; Suzuki, T. M.; Tanaka, H.; Kajino, T. Selective $\mathrm{CO}_{2}$ Conversion to Formate Conjugated with $\mathrm{H}_{2} \mathrm{O}$ Oxidation Utilizing Semiconductor/Complex Hybrid Photocatalysts. J. Am. Chem. Soc. 2011, 133 (39), 1524015243.

(4) Tu, W.; Zhou, Y.; Zou, Z. Photocatalytic Conversion of $\mathrm{CO}_{2}$ into Renewable Hydrocarbon Fuels: State-of-the-Art Accomplishment, Challenges, and Prospects. Adv. Mater. 2014, 26 (27), 46074626.

(5) Zhang, N.; Long, R.; Gao, C.; Xiong, Y. Recent Progress on Advanced Design for Photoelectrochemical Reduction of $\mathrm{CO}_{2}$ to Fuels. Sci. China Mater. 2018, 61 (6), 771-805.

(6) White, J. L.; Baruch, M. F.; Pander, J. E., III; Hu, Y.; Fortmeyer, I. C.; Park, J. E.; Zhang, T.; Liao, K.; Gu, J.; Yan, Y.; Shaw, T. W.; Abelev, E.; Bocarsly, A. B. Light-Driven Heterogeneous Reduction of Carbon Dioxide: Photocatalysts and Photoelectrodes. Chem. Rev. 2015, 115 (23), 12888-12935.

(7) Schreier, M.; Curvat, L.; Giordano, F.; Steier, L.; Abate, A.; Zakeeruddin, S. M.; Luo, J.; Mayer, M. T.; Gratzel, M. Efficient Photosynthesis of Carbon Monoxide From $\mathrm{CO}_{2}$ Using Perovskite Photovoltaics. Nat. Commun. 2015, 6, 7326.

(8) Sivula, K.; van de Krol, R. Semiconducting Materials for Photoelectrochemical Energy Conversion. Nat. Rev. Mater. 2016, 1, 15010.

(9) Urbain, F.; Tang, P.; Carretero, N. M.; Andreu, T.; Gerling, L. G.; Voz, C.; Arbiol, J.; Morante, J. R. A Prototype Reactor for Highly Selective Solar-Driven $\mathrm{CO}_{2}$ Reduction to Synthesis Gas Using Nanosized Earth-Abundant Catalysts and Silicon Photovoltaics. Energy \& Environ. Sci. 2017, 10, 2256-2266.

(10) Bushuyev, O. S.; De Luna, P.; Dinh, C. T.; Tao, L.; Saur, G.; van de Lagemaat, J.; Kelley, S. O.; Sargent, E. H. What Should We Make with $\mathrm{CO}_{2}$ and How Can We Make It? Joule. 2018, 2 (5), 825832.

(11) Dinh, C.-T.; Burdyny, T.; Kibria, M. G.; Seifitokaldani, A.; Gabardo, C. M.; Garcia de Arquer, F. P.; Kiani, A.; Edwards, J. P.; De Luna, P.; Bushuyev, O. S.; Zou, C.; Quintero-Bermudez, R.; Pang, Y.; Sinton, D.; Sargent, E. H. $\mathrm{CO}_{2}$ Electroreduction to Ethylene via Hydroxide-Mediated Copper Catalysis at an Abrupt Interface. Science 2018, 360, 783-787.

(12) Gao, S.; Lin, Y.; Jiao, X.; Sun, Y.; Luo, Q.; Zhang, W.; Li, D.; Yang, J.; Xie, Y. Partially Oxidized Atomic Cobalt Layers for Carbon Dioxide Electroreduction to Liquid Fuel. Nature 2016, 529 (7584), $68-71$.

(13) Liu, M.; Pang, Y.; Zhang, B.; De Luna, P.; Voznyy, O.; Xu, J.; Zheng, X.; Dinh, C. T.; Fan, F.; Cao, C.; de Arquer, F. P.; Safaei, T. S.; Mepham, A.; Klinkova, A.; Kumacheva, E.; Filleter, T.; Sinton, D.; Kelley, S. O.; Sargent, E. H. Enhanced Electrocatalytic $\mathrm{CO}_{2}$ Reduction via Field-Induced Reagent Concentration. Nature 2016, 537 (7620), 382-386.

(14) Zheng, X.; Ji, Y.; Tang, J.; Wang, J.; Liu, B.; Steinrück, H.-G.; Lim, K.; Li, Y.; Toney, M. F.; Chan, K.; Cui, Y. Theory-Guided Sn/ $\mathrm{Cu}$ Alloying for Efficient $\mathrm{CO}_{2}$ Electroreduction at Low Overpotentials. Nat. Catal. 2019, 2 (1), 55-61.

(15) Greenblatt, J. B.; Miller, D. J.; Ager, J. W.; Houle, F. A.; Sharp, I. D. The Technical and Energetic Challenges of Separating (Photo)electrochemical Carbon Dioxide Reduction Products. Joule 2018, 2 (3), 381-420.

(16) Kumar, B.; Atla, V.; Brian, J. P.; Kumari, S.; Nguyen, T. Q.; Sunkara, M.; Spurgeon, J. M. Reduced $\mathrm{SnO}_{2}$ Porous Nanowires with a High Density of Grain Boundaries as Catalysts for Efficient Electrochemical $\mathrm{CO}_{2}$-into- $\mathrm{HCOOH}$ Conversion. Angew. Chem., Int. Ed. 2017, 56, 3645-3649.

(17) Yin, G.; Abe, H.; Kodiyath, R.; Ueda, S.; Srinivasan, N.; Yamaguchi, A.; Miyauchi, M. Selective Electro- or Photo-Reduction of Carbon Dioxide to Formic Acid Using a Cu-Zn Alloy Catalyst. J. Mater. Chem. A 2017, 5, 12113-12119.
(18) Kortlever, R.; Peters, I.; Koper, S.; Koper, M. T. M. Electrochemical $\mathrm{CO}_{2}$ Reduction to Formic Acid at Low Overpotential and with High Faradaic Efficiency on Carbon-Supported Bimetallic Pd-Pt Nanoparticles. ACS Catal. 2015, 5 (7), 3916-3923.

(19) Lei, F.; Liu, W.; Sun, Y.; Xu, J.; Liu, K.; Liang, L.; Yao, T.; Pan, B.; Wei, S.; Xie, Y. Metallic Tin Quantum Sheets Confined in Graphene Toward High-Efficiency Carbon Dioxide Electroreduction. Nat. Commun. 2016, 7, 12697.

(20) Lv, W.; Bei, J.; Zhang, R.; Wang, W.; Kong, F.; Wang, L.; Wang, W. $\mathrm{Bi}_{2} \mathrm{O}_{2} \mathrm{CO}_{3}$ Nanosheets as Electrocatalysts for Selective Reduction of $\mathrm{CO}_{2}$ to Formate at Low Overpotential. ACS Omega 2017, 2 (6), $2561-2567$

(21) Zhang, S.; Kang, P.; Meyer, T. J. Nanostructured Tin Catalysts for Selective Electrochemical Reduction of Carbon Dioxide to Formate. J. Am. Chem. Soc. 2014, 136 (5), 1734-1737.

(22) Kalamaras, E.; Maroto-Valer, M. M.; Shao, M.; Xuan, J.; Wang, H. Solar Carbon Fuel via Photoelectrochemistry. Catal. Today 2018, $317,56-75$.

(23) Rao, K. R.; Pishgar, S.; Strain, J.; Kumar, B.; Atla, V.; Kumari, S.; Spurgeon, J. M. Photoelectrochemical Reduction of $\mathrm{CO}_{2}$ to $\mathrm{HCOOH}$ on Silicon Photocathodes with Reduced $\mathrm{SnO}_{2}$ Porous Nanowire Catalysts. J. Mater. Chem. A 2018, 6, 1736-1742.

(24) Won, D. H.; Chung, J.; Park, S. H.; Kim, E.-H.; Woo, S. I. Photoelectrochemical Production of Useful Fuels From Carbon Dioxide on s Polypyrrole-Coated P-ZnTe Photocathode Under Visible Light Irradiation. J. Mater. Chem. A 2015, 3, 1089-1095.

(25) Arai, T.; Sato, S.; Uemura, K.; Morikawa, T.; Kajino, T.; Motohiro, T. Photoelectrochemical Reduction of $\mathrm{CO}_{2}$ in Water under Visible-light Irradiation by a P-type InP Photocathode Modified with an Electropolymerized Ruthenium Complex. Chem. Commun. 2010, 46 (37), 6944-6946.

(26) Arai, T.; Tajima, S.; Sato, S.; Uemura, K.; Morikawa, T.; Kajino, T. Selective $\mathrm{CO}_{2}$ Conversion to Formate in Water using a CZTS Photocathode Modified with a Ruthenium Complex Polymer. Chem. Commun. 2011, 47 (47), 12664-12666.

(27) Deguchi, M.; Yotsuhashi, S.; Hashiba, H.; Yamada, Y.; Ohkawa, K. Enhanced Capability of Photoelectrochemical $\mathrm{CO}_{2}$ Conversion System Using an AlGaN/GaN Photoelectrode. Jpn. J. Appl. Phys. 2013, 52 (8S), 08JF07.

(28) Jiang, M.; Wu, H.; Li, Z.; Ji, D.; Li, W.; Liu, Y.; Yuan, D.; Wang, B.; Zhang, Z. Highly Selective Photoelectrochemical Conversion of Carbon Dioxide to Formic Acid. ACS Sustainable Chem. Eng. 2018, 6 (1), 82-87.

(29) Shen, Q.; Chen, Z.; Huang, X.; Liu, M.; Zhao, G. High-Yield and Selective Photoelectrocatalytic Reduction of $\mathrm{CO}_{2}$ to Formate by Metallic Copper Decorated $\mathrm{Co}_{3} \mathrm{O}_{4}$ Nanotube Arrays. Environ. Sci. Technol. 2015, 49 (9), 5828-5835.

(30) Magesh, G.; Kim, E. S.; Kang, H. J.; Banu, M.; Kim, J. Y.; Kim, J. H.; Lee, J. S. A Versatile Photoanode-Driven Photoelectrochemical System for Conversion of $\mathrm{CO}_{2}$ to Fuels with High Faradaic Efficiencies at Low Bias Potentials. J. Mater. Chem. A 2014, 2 (7), 2044.

(31) He, J.; Johnson, N. J. J.; Huang, A.; Berlinguette, C. P. Electrocatalytic Alloys for $\mathrm{CO}_{2}$ Reduction. ChemSusChem 2018, 11 (1), 48-57.

(32) Hori, Y. $\mathrm{CO}_{2}$-Reduction, Catalyzed by Metal Electrodes; John Wiley \& Sons, Ltd.: Hoboken, NJ. 2010.

(33) Wen, G.; Lee, D. U.; Ren, B.; Hassan, F. M.; Jiang, G.; Cano, Z. P.; Gostick, J.; Croiset, E.; Bai, Z.; Yang, L.; Chen, Z. Orbital Interactions in $\mathrm{Bi}-\mathrm{Sn}$ Bimetallic Electrocatalysts for Highly Selective Electrochemical $\mathrm{CO}_{2}$ Reduction toward Formate Production. Adv. Energy Mater. 2018, 8 (31), 1802427.

(34) Choi, S. Y.; Jeong, S. K.; Kim, H. J.; Baek, I.-H.; Park, K. T. Electrochemical Reduction of Carbon Dioxide to Formate on TinLead Alloys. ACS Sustainable Chem. Eng. 2016, 4 (3), 1311-1318.

(35) Luc, W.; Collins, C.; Wang, S.; Xin, H.; He, K.; Kang, Y.; Jiao, F. Ag-Sn Bimetallic Catalyst with a Core-Shell Structure for $\mathrm{CO}_{2}$ Reduction. J. Am. Chem. Soc. 2017, 139 (5), 1885-1893. 
(36) Lates, V.; Falch, A.; Kriek, R. J. Combinatorial Synthesis of Gold-Based Thin Films for Improved Electrocatalytic Conversion of $\mathrm{CO}_{2}$ to CO. Electrocatalysis 2015, 6 (3), 308-314.

(37) He, J. F.; Dettelbach, K. E.; Huang, A. X.; Berlinguette, C. P. Brass and Bronze as Effective $\mathrm{CO}_{2}$ Reduction Electrocatalysts. Angew. Chem. 2017, 129, 16806-16809.

(38) Singh, M. R.; Clark, E. L.; Bell, A. T. Thermodynamic and Achievable Efficiencies for Solar-Driven Electrochemical Reduction of Carbon Dioxide to Transportation Fuels. Proc. Natl. Acad. Sci. U. S. A. 2015, 112 (45), E6111-E6118.

(39) Walczak, K. A.; Segev, G.; Larson, D. M.; Beeman, J. W.; Houle, F. A.; Sharp, I. D. Hybrid Composite Coatings for Durable and Efficient Solar Hydrogen Generation under Diverse Operating Conditions. Adv. Energy Mater. 2017, 7 (13), 1602791.

(40) Sun, K.; Park, N.; Sun, Z.; Zhou, J.; Wang, J.; Pang, X.; Shen, S.; Noh, S. Y.; Jing, Y.; Jin, S.; Yu, P. K. L.; Wang, D. Nickel Oxide Functionalized Silicon for Efficient Photo-oxidation of Water. Energy Environ. Sci. 2012, 5 (7), 7872.

(41) Sun, K.; Shen, S.; Liang, Y.; Burrows, P. E.; Mao, S. S.; Wang, D. Enabling Silicon for Solar-Fuel Production. Chem. Rev. 2014, 114 (17), 8662-8719.

(42) Crespo-Quesada, M.; Pazos-Outon, L. M.; Warnan, J.; Kuehnel, M. F.; Friend, R. H.; Reisner, E. Metal-Encapsulated Organolead Halide Perovskite Photocathode for Solar-Driven Hydrogen Evolution in Water. Nat. Commun. 2016, 7, 12555.

(43) Da, P.; Cha, M.; Sun, L.; Wu, Y.; Wang, Z. S.; Zheng, G. HighPerformance Perovskite Photoanode Enabled by Ni Passivation and Catalysis. Nano Lett. 2015, 15 (5), 3452-3457.

(44) Zhang, H.; Yang, Z.; Yu, W.; Wang, H.; Ma, W.; Zong, X.; Li, C. A Sandwich-Like Organolead Halide Perovskite Photocathode for Efficient and Durable Photoelectrochemical Hydrogen Evolution in Water. Adv. Energy Mater. 2018, 8 (22), 1800795.

(45) Gao, L.-F.; Luo, W.-J.; Yao, Y.-F.; Zou, Z.-G. An All-inorganic Lead Halide Perovskite-Based Photocathode for Stable Water Reduction. Chem. Commun. 2018, 54, 11459-11462.

(46) Xing, G.; Mathews, N.; Sun, S.; Lim, S. S.; Lam, Y. M.; Grätzel, M.; Mhaisalkar, S.; Sum, T. C. Long-Range Balanced Electronand Hole-Transport Lengths in Organic-Inorganic $\mathrm{CH}_{3} \mathrm{NH}_{3} \mathrm{PbI}_{3}$. Science 2013, 342 (6156), 344-347.

(47) Zhumekenov, A. A.; Saidaminov, M. I.; Haque, M. A.; Alarousu, E.; Sarmah, S. P.; Murali, B.; Dursun, I.; Miao, X.-H.; Abdelhady, A. L.; Wu, T.; Mohammed, O. F.; Bakr, O. M. Formamidinium Lead Halide Perovskite Crystals with Unprecedented Long Carrier Dynamics and Diffusion Length. ACS Energy Lett. 2016, 1, 32-37.

(48) Shi, D.; Adinolfi, V.; Comin, R.; Yuan, M.; Alarousu, E.; Buin, A.; Chen, Y.; Hoogland, S.; Rothenberger, A.; Katsiev, K.; Losovyj, Y.; Zhang, X.; Dowben, P. A.; Mohammed, O. F.; Sargent, E. H.; Bakr, O. M. Low Trap-State Density and Long Carrier Diffusion in Organolead Trihalide Perovskite Single Crystals. Science 2015, 347 (6221), 519522.

(49) Research Cell Efficiency Records. http://www.nrel.gov/pv/ (accessed May 6th, 2019).

(50) Zhao, Y.; Zhang, Z.; Dang, H. Synthesis of In-Sn Alloy Nanoparticles by a Solution Dispersion Method. J. Mater. Chem. 2004, 14 (3), 299-302.

(51) Manasijević, I.; Balanović, L.; Grgurić, T. H.; Minić, D.; Gorgievski, M. Study of Microstructure and Thermal Properties of the Low Melting Bi-In-Sn Eutectic Alloys. Mater. Res. 2018, 21, No. e20180501.

(52) Kumar, V. B.; Kimmel, G.; Porat, Z.; Gedanken, A. Formation of Particles of Bismuth-Based Binary Alloys and Intermetallic Compounds by Ultrasonic Cavitation. New J. Chem. 2015, 39, 5374-5381.

(53) Sengupta, S.; Soda, H.; Mclean, A. Microstructure and Properties Of a Bismuth-Indium-Tin Eutectic Alloy. J. Mater. Sci. 2002, 37, 1747-1758.

(54) Wang, F.; Zhou, L.; Wang, X.; He, P. Microstructural Evolution and Joint Strength of $\mathrm{Sn}-58 \mathrm{Bi} / \mathrm{Cu}$ Joints Through Minor Zn Alloying
Substrate During Isothermal Aging. J. Alloys Compd. 2016, 688, 639648.

(55) Hori, Y.; Wakebe, H.; Tsukamoto, T.; Koga, O. Electrocatalytic Process of $\mathrm{CO}$ Selectivity in Electrochemical Reduction of $\mathrm{CO}_{2}$ at Metal Electrodes in Aqueous Media. Electrochim. Acta 1994, 39 (1112), 1833-1839.

(56) Jedidi, A.; Rasul, S.; Masih, D.; Cavallo, L.; Takanabe, K. Generation of $\mathrm{Cu}-\mathrm{In}$ Alloy Surfaces From $\mathrm{CuInO}_{2}$ as Selective Catalytic Sites for $\mathrm{CO}_{2}$ Electroreduction. J. Mater. Chem. A 2015, 3, 19085-19092.

(57) Vasileff, A.; Zheng, Y.; Qiao, S. Z. Carbon Solving Carbon's Problems: Recent Progress of Nanostructured Carbon-Based Catalysts for the Electrochemical Reduction of $\mathrm{CO}_{2}$. Adv Energy Mater. 2017, 7 (21), 1700759.

(58) Lee, C. W.; Hong, J. S.; Yang, K. D.; Jin, K.; Lee, J. H.; Ahn, H.Y.; Seo, H.; Sung, N.-E.; Nam, K. T. Selective Electrochemical Production of Formate from Carbon Dioxide with Bismuth-Based Catalysts in an Aqueous Electrolyte. ACS Catal. 2018, 8 (2), 931937.

(59) Rosen, J.; Hutchings, G. S.; Lu, Q.; Rivera, S.; Zhou, Y.; Vlachos, D. G.; Jiao, F. Mechanistic Insights into the Electrochemical Reduction of $\mathrm{CO}_{2}$ to $\mathrm{CO}$ on Nanostructured Ag Surfaces. ACS Catal. 2015, 5 (7), 4293-4299.

(60) Coridan, R. H.; Nielander, A. C.; Francis, S. A.; McDowell, M. T.; Dix, V.; Chatman, S. M.; Lewis, N. S. Methods for Comparing the Performance of Energy-Conversion Systems for use in Solar Fuels and Solar Electricity Generation. Energy Environ. Sci. 2015, 8, 2886-2901. 